\title{
Letter
}

\section{On the Physics of the Bone Fracture}

\author{
Martin G. Abrahamyan ${ }^{1,2}$ \\ ${ }^{1}$ Department of Physics, Yerevan State University, Yerevan, Armenia \\ ${ }^{2}$ Department of Medical Physics, Yerevan "Haybusak" University, Yerevan, Armenia
}

Email address:

martin.abrahamyan@ysu.am

\section{To cite this article:}

Martin G. Abrahamyan. On the Physics of the Bone Fracture. International Journal of Clinical and Experimental Medical Sciences. Vol. 3, No. 6, 2017, pp. 74-77. doi: 10.11648/j.ijcems.20170306.12

Received: January 27, 2017; Accepted: March 1, 2017; Published: November 28, 2017

\begin{abstract}
The mechanics of the bones fracture is studied. The usefulness of simple physical consideration for studying of the bone fracture phenomenon is shown. Some quantitative estimations of potential energy of the bone elastic deformations as well as of impulsive forces for bone fracture, caused by sudden collision, by a fall, by road traffic accident etc., have been obtained. The dependences of the impulsive forces on the relative velocity of colliding bodies and of collision time have been established.
\end{abstract}

Keywords: Bone Fracture, Impulsive Force, Sudden Collision

\section{Introduction}

Bone is the main material of the musculoskeletal device. In the simplified look it is possible to consider that $2 / 3$ masses of a compact bone tissue ( 0.5 of the volume) is inorganic material, mineral substance of a bone - a hydroxyapatite $\mathrm{Ca}_{10}\left(\mathrm{PO}_{4}\right)_{6} \mathrm{Ca}(\mathrm{OH})_{2}$. This substance is presented in the form of microscopic crystals. The rest the bone consists of an organic material, mainly collagen (high-molecular connection, the fibrous protein possessing high elasticity) [1,2]. Crystals of a hydroxyl of apatite are located between collagenic fibers. Density of a bone tissue equals $\cong 2.4 \mathrm{~g} / \mathrm{cm}^{3}$. Its mechanical properties depend on many factors, including age, individual conditions of growth of an organism [3].

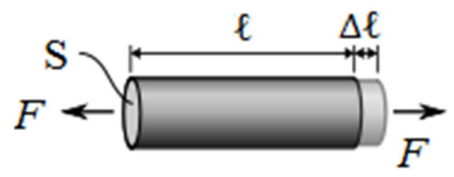

Figure 1. Stretched cylindrical bone.

A bone fracture (the medical term for a broken bone) can be the result of a high force impact or stress, or a minimal trauma injury as a result of certain medical conditions that weaken the bones (such as osteoporosis, bone cancer, or osteogenesis imperfecta).
The composite structure of a bone gives it the necessary mechanical properties: hardness, elasticity and durability [4-6]. Dependence of stress $\sigma$ (the internal force, $\mathrm{F}$, per unit area acting on the bone: $\sigma=\mathrm{F} / \mathrm{S}, \mathrm{S}$ is the area of the force action), on longitudinal strain $\varepsilon$ (the fractional change in the bone length, $\ell: \varepsilon=\Delta \ell / \ell, \Delta \ell$ is the measure of the bone deformation, Figure 1)

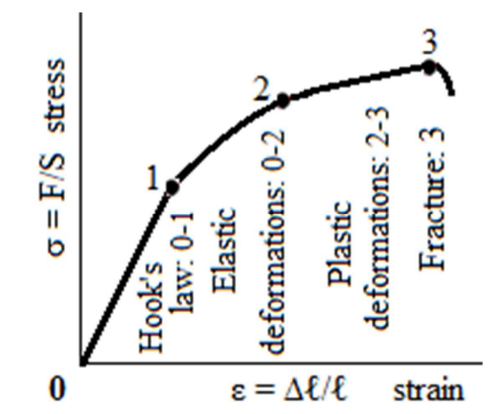

Figure 2. Stress - strain dependence for bone.

$$
\sigma=\mathrm{f}(\varepsilon)
$$

for a compact bone tissue in norm approximately looks like the curve shown in Figure 2. That is, is similar to the dependence for a firm physical body; at small deformations Hook's law takes place (the range $0-1$ in Figure 2) $[4,5]$ :

$$
\sigma / \varepsilon=\mathrm{Y}
$$


where $\mathrm{Y}$ is the Young modulus, an important physical characteristic of the bone, the value which, as well as the rupture strength value for different types of deformations are shown in the Table 1.

A stretched (or compressed) bone contains potential energy; that is, work can be done by the stretched bone (like a spring) when the stretching force is removed. The potential energy, $U$, stored in the bone is given by formula [5]:

$$
\mathrm{U}=\mathrm{k}(\Delta \ell)^{2} / 2 \text {. }
$$

An elastic bone under stress is analogous to a spring with a spring constant [5]:

$$
\mathrm{k}=\mathrm{YS} / \ell \text {. }
$$

By analogy with the spring, the potential energy stored in a stretched or compressed bone is given by formula [4-6]:

$$
\mathrm{U}=\mathrm{YS}(\Delta \ell)^{2} / 2 \ell \text {. }
$$

Table 1. The Young modulus and the rupture strength values for the bone and tendon [3-6].

\begin{tabular}{lll}
\hline Material & Young's modulus $\left(\mathbf{N} / \mathbf{s m}^{2}\right)$ & Rupture strength $\left(\mathbf{N} / \mathbf{s m}^{2}\right)$ \\
\hline \multirow{3}{*}{ Bone } & \multirow{2}{*}{$14 \cdot 10^{5}$} & $10 \cdot 10^{3}-$ compression \\
& & $8.3 \cdot 10^{3}-$ stretch \\
& & $2.75 \cdot 10^{3}-$ twist \\
Tendon & - & $6.9 \cdot 10^{3}-$ stretch \\
\hline
\end{tabular}

\section{Energy Considerations}

Knowledge of the maximum energy that parts of the body can safely absorb allows us to estimate the possibility of injury under various circumstances. We shall first calculate the amount of energy required to break a bone of area Sand length $\ell$. Assume that the bone remains elastic until fracture. Let us designate the breaking stress of the bone by $\sigma_{B}$. The corresponding force $\mathrm{F}_{\mathrm{B}}$ that will fracture the bone, from Eq. (2), considering a definition of the strain, $\varepsilon$, and the stress, $\sigma$, is

$$
\mathrm{F}_{\mathrm{B}}=\sigma_{\mathrm{B}} \mathrm{S}=\mathrm{YS} \Delta \ell / \ell \text {. }
$$

The value of compression $\Delta \ell$ at the breaking point is, therefore,

$$
\Delta \ell=\sigma_{\mathrm{B}} \ell / \mathrm{Y}
$$

The energy of the compressed bone at the point of fracture is given by Eq. (4), which, taking into account Eq. (6), has the form $[5,6]$

$$
\mathrm{U}=\ell \mathrm{S} \sigma_{\mathrm{B}}^{2} / 2 \mathrm{Y}
$$

As an example, we consider the fracture of two leg bones that have a combined length of about $\ell \cong 90 \mathrm{~cm}$ and an average area of about $S \cong 6 \mathrm{~cm}^{2}$. From Table 1, the breaking stress of bone equals $\sigma_{\mathrm{B}}=10^{4} \mathrm{~N} / \mathrm{sm}^{2}$. The Young's modulus for the bone in norm is $\mathrm{Y}=14 \cdot 10^{5} \mathrm{~N} / \mathrm{cm}^{2}$. The total energy absorbed by the bones of one leg at the point of compressive fracture is, from Eq. (7)

$$
\mathrm{U}=6 \cdot 90 \cdot 10^{8} / 14 \cdot 10^{5} \mathrm{~N} \cdot \mathrm{cm}=192.5 \mathrm{~J} .
$$

The combined energy in the two legs is twice this value, or $385 \mathrm{~J}$. This is the amount of energy in the impact of a $70-\mathrm{kg}$ person jumping from a height of $56 \mathrm{~cm}$, given by the product $m g h$ (the potential energy of person of the mass $m$ on height $h$; $g=9.8 \mathrm{~m} / \mathrm{s}^{2}$ is the freefall acceleration [5]). If all this energy is absorbed by the leg bones, they may fracture. But we know that it is certainly possible to jump safely from a height considerably greater than $56 \mathrm{~cm}$ if, on landing, the joints of the body bend and the energy of the fall is redistributed over the body to reduce the chance of fracture.

\section{The Bone Fracture in a Sudden Collision}

The bone fracture can be studied dynamically by means of impulsive force. The forces that two colliding bodies exert on one another act for a short time giving a brief but strong push is called impulsive force $[5,6]$. Any collision, road traffic accident, fights and so on causes an impulsive force emergence. When a bullet strikes a glass, an impulsive force acts on the glass. The impulsive force is much stronger than any other force available at that point of time and acts on an object for a very short interval during collision or explosion.

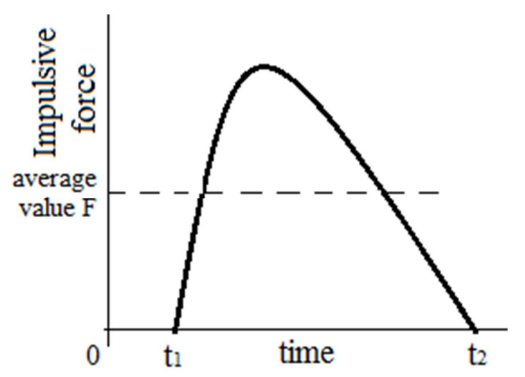

Figure 3. Dependence of Impulsive force on time. The dotted line indicates the average value of the impulsive force.

In a sudden collision, a large force is exerted for a short period of time on the colliding objects. The force starts at zero, increases to some maximum value, and then decreases to zero again (Figure 3). The main utility of the concept is in the study of the average impact force during collisions. For collisions, the mass and change in velocity are often readily measured, but the force during the collision is not. If the time of collision can be measured, then the average force of the impact can be calculated. The time interval $t_{2}-t_{1}=\Delta t$ during which the force acts on the body is the duration of the collision. Such an impulsive force can be estimated from the relationship between the force, $\mathrm{F}$, and the linear momentum, $\mathrm{p}=\mathrm{mv}$ ( $\mathrm{v}$ is velocity). Using Newton's second law, we get [5-7]:

$$
\mathrm{F}=\Delta \mathrm{p} / \Delta \mathrm{t}=\mathrm{m}\left(\mathrm{v}_{\mathrm{f}}-\mathrm{v}_{\mathrm{i}}\right) / \Delta \mathrm{t}
$$

Here $m_{i}=p_{i}$ is the initial linear momentum of the object and $\mathrm{mv}_{\mathrm{f}}=\mathrm{p}_{\mathrm{f}}$ is the final linear momentum after the collision. The duration of collision, $\Delta \mathrm{t}$, depends on the type of collision, and particularly (more important!) on the stiffness of the surfaces of the colliding bodies. For example, if the duration 
of a collision of cylindrical bone to a wall is: $\Delta t=5 \cdot 10^{-3} \mathrm{sec}$, and the change in the linear momentum is $(1 \mathrm{~kg}$ mass, moving at a speed of $10 \mathrm{~m} / \mathrm{sec}$ )

$$
\mathrm{m} \Delta \mathrm{v}=1 \mathrm{~kg} \cdot 10 \mathrm{~m} / \mathrm{sec}=10 \mathrm{~kg} \cdot \mathrm{m} / \mathrm{sec}
$$

then the average force that acts during the collision is

$$
\mathrm{F}=10 \mathrm{~kg} \cdot \mathrm{m} / \mathrm{sec} / 5 \cdot 10^{-3} \mathrm{sec}=2 \cdot 10^{3} \mathrm{~N} .
$$

Note that the magnitude of the impulsive force (8) is inversely proportional to the collision time; that is, the collision force is larger in a short collision than in a longer collision.

\section{Fracture Due to a Fall}

When a person falls from a height $h$, his/her velocity when hitting the ground, is [4-6]

$$
\mathrm{v}=\sqrt{ } 2 \mathrm{gh}
$$

The linear momentum at the moment of the impact, $p_{i}$, of a person of mass $m$ is

$$
\mathrm{mv}_{\mathrm{i}}=\mathrm{m} \sqrt{ } 2 \mathrm{gh} .
$$

After the impact the body is at rest, and its linear momentum is therefore zero $\left(\mathrm{mv}_{\mathrm{f}}=0\right)$. The change in linear momentum is given by Eq. (10). Therefore the average impact force equals

$$
F=(m / \Delta t) \sqrt{ } 2 g h .
$$

The duration of the collision $\Delta \mathrm{t}$ is difficult to determine precisely. It depends on the type of collision. If the impact surface is hard, the collision time is very short, a few milliseconds; if it is soft, the duration of the collision is longer. For example, to reduce the impulsive force acting on the leg of an athlete, the long jump pit is filled with sand to increase the collision time when athlete lands on it. During a high jump, a high jumper will land on a thick, soft mattress after the jump. This is to increase the reaction time and hence reduces the impulsive force acting on the high jumper.

If the impact area is concrete, and if the person falls with his/her joints rigidly locked, the collision time will be about $10^{-2} \mathrm{sec}$. The collision time is considerably longer if the person bends his/her knees.

In the Table, the force per unit area that may cause a bone fracture is $10^{4} \mathrm{~N} / \mathrm{cm}^{2}$. If the person falls flat on his/her heels, the area of impact maybe about $2 \mathrm{~cm}^{2}$. Therefore, the force that will cause fracture is

$$
\mathrm{F}_{\mathrm{B}}=2 \mathrm{~cm}^{2} \cdot 10^{4} \mathrm{~N} / \mathrm{cm}^{2}=2 \cdot 10^{4} \mathrm{~N} \text {. }
$$

The impact force may also be calculated by the distance that the center of mass of the body travels during the collision under the action of the impulsive force. The forward motion of the passenger in a car must be stopped in about $30 \mathrm{~cm}$ of motion if the contact with hard surfaces of the car is to be avoided. The average deceleration is given by the formula $a=$ $v^{2} / 2 s$, where $v$ is the initial velocity of the car (and the passenger) and $\mathrm{s}$ is the distance over which the deceleration occurs. The average impulsive force is [5-7]

$$
\mathrm{F}=\mathrm{m} a=\mathrm{mv}^{2} / 2 \mathrm{~s},
$$

where $\mathrm{m}$ is the mass of the passenger. For a $70 \mathrm{~kg}$ person with a $30 \mathrm{~cm}$ allowed stopping distance, the average force is $\mathrm{F}=$ $70 \cdot \mathrm{v}^{2} / 2 \cdot 0.3=117 \cdot \mathrm{v}^{2} \mathrm{~N}$. At $\mathrm{v}=10 \mathrm{~m} / \mathrm{sec}$ impact speed, the average stopping force is $\cong 1.2 \cdot 10^{4} \mathrm{~N}$, which can be dangerous for the passenger.

In road traffic accidents the value of the impulsive forces acting on the passengers is proportional to the square of the relative velocity of the colliding vehicles. For this reason, the strongest impulsive forces are exposed to the passengers in the accidents of oppositely moving vehicles.

\section{Conclusions}

Most bone fractures are caused by falls and vehicle accidents. The basic types of traumatic bone fracture: a Greenstick fracture (in which the bone is bent), a transverse fracture, an oblique fracture, a comminuted fracture etc. are caused in essentially by different types of collisions and impacts and can have dangerous complications which include damages to blood vessels or nerves and osteomyelitis (inflammation of bone or bone marrow) [8-10]. The simple physical study of this phenomenon, allows to establish the dependence of the impulsive forces arising during collisions and impacts on the relative velocity of colliding bodies and of the collision time, as well as make some quantitative estimations of the energy and the forces for bone fracture caused by collisions, by a fall, by road traffic accident etc.

\section{References}

[1] J. D. Currey, "The Structure of Bone Tissue", pp. 12-14 in Bones: Structure and Mechanics. Princeton University Press, Princeton, 2002, ISBN: 9781400849505.

[2] J. Hall, Textbook of Medical Physiology (12th ed.). Philadelphia: Elsevier, 2011, pp. 957-960. ISBN 978-08089-2400-5.

[3] K. Vincent, "Topic 3: Structure and Mechanical Properties of Bone", BENG 112A Biomechanics, Winter Quarter, 2013, Department of Bioengineering, University of California.

[4] M. G. Abrahamyan, The course of medical and biological physics, Lambert Academic Publishing, 2016, ISBN: 978-3-659-96911-9, 210p.

[5] M. G. Abrahamyan, Physical principles of mechanics, Lambert Academic Publishing, 2016, ISBN: 978-3-330-02108-2, 103p.

[6] P. Davidovits, Physics in biology and medicine, Academic Press, 2008, ISBN: 978-0-12-369411-9, 571p.

[7] M. G. Abrahamyan, Physics and Applications in Medicine, Edit Print, 2015, ISBN: 978-9939-52-968-4, 262p. 
[8] C. R. Perry, S. Rice, A. Rao, R. Burdge, Posterior fracture-dislocation of the distal part of the fibula. Mechanism and staging of injury, The Journal of bone and joint surgery, vol. 65 (8): 1149-57, 1983.

[9] Marsh JL, Slongo TF, Agel J, Broderick JS, Creevey W, DeCoster TA, Prokuski L, Sirkin MS, Ziran B, Henley B, Audigé L, Fracture and dislocation classification compendium,
Journal of orthopedic trauma, vol. 21 (10 Suppl): S1-133. 2007.

[10] D. K. Witmer, S. T. Marshall, B. D. Browner, "Emergency Care of Musculoskeletal Injuries", In Townsend, Courtney M.; Beauchamp, R. Daniel; Evers, B. Mark; Kenneth L. Sabiston; Textbook of Surgery (20th ed.), Elsevier, 2016, ISBN 978-0-323-40163-0. 